\title{
Permeability properties of tumor surrogate blood vessels induced by VEGF-A
}

\author{
Janice A Nagy*, Dian Feng ${ }^{* \dagger}$, Eliza Vasile ${ }^{*, \ddagger}$, Wendy H Wong, Shu-Ching Shih, \\ Ann M Dvorak and Harold F Dvorak
}

Department of Pathology, Beth Israel Deaconess Medical Center and Harvard Medical School, Boston, $M A, U S A$

\begin{abstract}
Malignant tumors generate new blood vessels by secreting growth factors, particularly members of the vascular permeability factor/vascular endothelial growth factor (VPF/VEGF) family. Overall, the new blood vessels that form are hyperpermeable to plasma proteins, a property that is thought to be important for generating new stroma. However, tumor blood vessels are structurally heterogeneous and include microvessels of at least the following distinct types: mother vessels (MV), glomeruloid microvascular proliferations (GMP), arterio-venouslike vascular malformations and capillaries. Our goal was to determine whether macromolecular tracers leaked from all or from only a subset of these vessel types and to elucidate the extravasation pathways. As blood vessels are only a minor component of tumors, and therefore, difficult to study in situ, we used an adenoviral vector to express VEGF-A ${ }^{164}$, the most important member of the VPF/VEGF family, in mouse tissues. So expressed, VEGF-A ${ }^{164}$ induces large numbers of surrogate vessels of each type found in tumors in a highly reproducible manner. Overall permeability to plasma proteins was assessed qualitatively with Evan's blue dye and quantitatively with a dual tracer method employing radioactive albumin. Leaky vessels were identified by confocal microscopy (FITC-dextran) and by electron microscopy (ferritin). MV, and to a lesser extent GMP, were found to be hyperpermeable but capillaries and vascular malformations were not. Ferritin extravasated primarily by two trans-cellular routes, vesiculo-vacuolar organelles (VVOs) and fenestrae. This occurred despite a considerable reduction in VVO frequency as VVO membranes translocated to the plasma membrane during MV formation. However, reduction in the number and complexity of VVOs was offset by extensive endothelial cell thinning and a greatly shortened extravasation pathway. Extrapolating these findings to tumors predicts that only a subset of tumor vessels, MV and GMP, is hyperpermeable, and that measures of overall vessel permeability greatly underestimate the permeability of individual MV and GMP.

Laboratory Investigation (2006) 86, 767-780. doi:10.1038/labinvest.3700436; published online 29 May 2006
\end{abstract}

Keywords: VEGF-A; permeability; mother vessels; GMP; VVOs; vascular malformations

Vascular permeability factor/vascular endothelial growth factor (VPF/VEGF, VEGF-A) is a multifunctional cytokine that is over-expressed by most malignant tumors. ${ }^{1-4}$ One isoform (mouse VEGF$\mathrm{A}^{164}$, human VEGF-A ${ }^{165}$ ) is widely regarded as the single most important angiogenic tumor cytokine. VEGF-A ${ }^{164 / 5}$ renders normal microvessels hyperpermeable to plasma and plasma proteins and does so with a potency some 50000 times that of

Correspondence: Dr HF Dvorak, MD, Department of Pathology, Beth Israel Deaconess Medical Center, 330 Brookline Avenue, Research North, 227C, Boston, MA 02215, USA.

E-mail: hdvorak@bidmc.harvard.edu

*These authors contributed equally to the experimental work.

Current address: Department of Pathology, State University of New York, Buffalo, NY, USA.

${ }^{\ddagger}$ Current address: Center for Cancer Research, Massachusetts Institute of Technology, Cambridge, MA, USA.

Received 28 February 2006; revised 13 April 2006; accepted 19 April 2006; published online 29 May 2006 histamine. ${ }^{1,4,5}$ Consistent with VEGF-A ${ }^{164 / 5}$ 's vascular permeabilizing activity and its nearly universal expression by malignant tumor cells, tumor blood vessels are, overall, four to 10 times leakier to plasma proteins and other circulating macromolecules than their counterparts in normal tissues (reviewed in Dvorak et $a l^{3}$ ). Tumor vessel permeability is thought to contribute importantly to the induction of tumor stroma. ${ }^{1-3,5-10}$ Hyperpermeable tumor vessels leak plasma fibrinogen, which clots to deposit fibrin in the extravascular space; fibrin, in turn, provides a provisional matrix that fosters generation of mature vascularized stroma. Recently, other members of the VEGF family, including placenta growth factor (PlGF), have also been found to have significant roles in tumor angiogenesis. ${ }^{11,12}$

Although it is widely accepted that the tumor vascular bed is, overall, hyperpermeable to plasma proteins, two important questions have not been resolved. The first concerns the identity of the blood 
vessels in tumors that are hyperpermeable. The tumor microvasculature differs markedly from that of normal vascular beds with respect to organization, structure and function (reviewed in Dvorak et $a l^{10,13}$, Dvorak ${ }^{14}$ ). Recent studies have identified several distinct types of vessels in many human and animal tumors: 'mother' vessels (MV), glomeruloid microvascular proliferations (GMP), arterio-venous-like vascular malformations and capillaries. ${ }^{14-19}$ Using an adenoviral vector expressing VEGF-A ${ }^{164}$, we have been able to generate large numbers of surrogate vessels of each of these distinct types in mouse tissues in the absence of tumor cells. ${ }^{4,14,17,18} \mathrm{MV}$ are the first type of new vessels to form in tumors ${ }^{15,20}$ and in response to Ad-VEGF$\mathrm{A}^{164} .^{17}$ They arise from preexisting normal venules and are large, thin-walled, serpentine, pericyte-poor sinusoids that overexpress both of the VEGF-A receptor tyrosine kinases (VEGFR-1, VEGFR-2). MV then evolve into GMP and vascular malformations and also into structurally normal capillaries by a process of transcapillary bridging. ${ }^{9,17}$ GMP are clusters of small vascular channels lined by endothelium and enveloped by proliferating pericytes and reduplicated basal lamina. ${ }^{18}$ Vascular malformations are large vascular channels, essentially mother vessels (MV) that have become stabilized by acquiring an irregular smooth muscle cell coat. ${ }^{4,17,21}$ The permeability properties of these distinctly different tumor vessel types have not been investigated.

A second unresolved question concerns the anatomic pathways by which macromolecules leak from tumor vessels. In normal tissues, venules are the segment of the microvasculature that is rendered permeable to plasma proteins in response to VEGFA, histamine and other inflammatory mediators. ${ }^{22}$ However, opinion is divided as to whether the leakage induced by these mediators proceeds by way of inter-endothelial cell or trans-endothelial cell pathways (or both). ${ }^{16,23-26}$ The same debate extends to leaky tumor blood vessels. ${ }^{16,20,27,28}$

The goals of the present investigation were to evaluate the permeability status of each of the different types of tumor surrogate blood vessels induced by Ad-VEGF-A ${ }^{164}$ and to elucidate the pathways by which circulating macromolecules extravasated from them. We chose this approach because the kinetics are highly reproducible, allowing us to study each of the types of vessels found in tumors in large numbers. It therefore avoided the sampling problem encountered in tumors where blood vessels comprise only a small fraction of the tumor mass and where secondary issues such as necrosis and inflammation may affect vascular structure and function.

\section{Materials and methods}

\section{Adenoviral Vectors and Animals}

Adenoviral vectors containing the coding regions of murine VEGF-A ${ }^{164}$, placenta growth factor (PlGF-2) and LacZ have been described previously. ${ }^{12,17,29}$ Immediately before injection, vectors were diluted in PBS-3\% glycerol and injected into the dorsal ear skin of 4- to 6-week-old female athymic $\mathrm{Nu} / \mathrm{Nu}$ mice (National Cancer Institute, Bethesda, MD) in a volume of $10 \mu \mathrm{l}$ using a Hamilton syringe fitted with a fixed $26 \mathrm{~g}$ needle. Immuno-incompetent nude mice were used for these studies in order to avoid an immune response against the viral vector. Ears were chosen as injection sites because the evolving angiogenic response can be followed visibly over time in the living animal. Animal protocols were approved by the BIDMC Institutional Animal Care and Use Committee.

\section{Quantitative Real-Time PCR}

In all, $8 \mathrm{~mm}$ punch biopsies that encompassed the entire reaction sites were collected from injected ears. Total RNA was prepared using the RNeasy RNA extraction kit with DNase-I treatment following the manufacturer's protocol (Qiagen). To generate cDNA, total RNA (100 ng) from each of triplicate samples was mixed and converted into cDNA using random primers and SuperscriptIII reverse transcriptase (Invitrogen, Carlsbad, CA, USA). All cDNA samples were aliquoted and stored at $-80^{\circ} \mathrm{C}$. Primers were designed using the Primer Express oligo design software (Applied BioSystems, Foster City, CA, USA) and were synthesized by Integrated DNA Technologies (Coralville, IA, USA). All primer sets were subjected to rigorous database searches to identify potential conflicting transcript matches to pseudogenes or homologous domains within related genes. Amplicons generated from the primer set were analyzed for melting point temperatures using the first derivative primer melting curve software supplied by Applied BioSystems. The real-time PCR primer sequences for murine VEGF-A are: forward primer, 5'-AACAAAGCCAGAAAATCACTGTGA-3'; reverse primer, 5'-CGGATCTTGGACAAACAAAT GC-3'. The sequences for murine PlGF-2 are: forward primer, 5'-TCGCTGTAGTGGCTGCTGTG-3'; reverse primer, $5^{\prime}$-CTGCATAGTGATGTTGGCTGTCT- ${ }^{\prime}$. The SYBR Green I assay and the ABI Prism 7500 Sequence Detection System were used for detecting real-time PCR products from the reverse transcribed cDNA samples, as described previously. ${ }^{30} 18 \mathrm{~S}$ rRNA, which is known to be the most uniformly expressed housekeeping gene, ${ }^{31}$ was used as the normalizer. PCR reactions for each sample were performed in duplicate and copy numbers were measured as described previously. ${ }^{30}$ The level of target gene expression was normalized against the $18 \mathrm{~S}$ rRNA expression in each sample and the data is reported as mRNA copies per $10^{6} 18 \mathrm{~S}$ rRNA copies.

\section{Quantitative Analysis of VEGF-A Protein by ELISA}

The amount of VEGF protein present in the AdVEGF-A $^{164}$ injected ears was quantified using a 
murine VEGF-A-specific ELISA (Quantikine Mouse VEGF Immunoassay Kit; R\&D Systems, Minneapolis, MN, USA). At various time points following AdVEGF-A ${ }^{164}$ injection, animals were euthanized and $8 \mathrm{~mm}$ punch biopsy samples of the injected ears were homogenized in $1 \mathrm{ml}$ of T-PER (tissue protein extraction reagent, Pierce, Rockford, IL, USA) containing $10 \mu \mathrm{l}$ of each of the following: HALT protease inhibitor cocktail (Pierce), Phosphatase Inhibitor Cocktails I \& II (Sigma), and 0.5 M EDTA. Lysates were centrifuged at 14000 r.p.m. for $30 \mathrm{~min}$ at $4^{\circ} \mathrm{C}$ to pellet insoluble material and the supernatant was removed and stored at $-20^{\circ} \mathrm{C}$ prior to use. Tissue lysates were thawed, diluted in lysis buffer, and analyzed according to the manufacturer's instructions. Four to six independent samples were analyzed at each time point and each sample was analyzed in duplicate. The VEGF-A concentration in each sample was corrected for protein recovery using a correction factor that was determined as follows. A known volume of purified mouse VEGF$\mathrm{A}^{165}$ protein was injected into ear skin of control animals, and the ear tissue was processed as described above for ELISA. The correction factor for recovery was calculated by comparing the amount of purified VEGF that was detected in this ear specimen by ELISA with the amount of VEGF that was determined by ELISA when the same volume of purified VEGF was injected directly into the well of the ELISA microtiter plate. The mean corrected amount of VEGF present in the Ad-VEGF$\mathrm{A}^{164}$ ears is reported as $\mathrm{ng} / \mathrm{ear} \pm$ s.e.

\section{Qualitative Analysis of Angiogenesis and Plasma Extravastion Using Evan's Blue Dye as Tracer}

For qualitative evaluation of ear vessel permeability, mice were anesthetized with Avertin (tribromoethanol, $200 \mathrm{mg} / \mathrm{kg}$ ) and ears were photographed using a Wild M-400 Photomacroscope. Mice were then injected i.v. with $100 \mu \mathrm{l}$ 0.5\% Evan's Blue (Sigma, St Louis, MO, USA) in saline and 30 min later, ears were photographed again.

\section{Quantitative Analysis of Albumin Leakage Rate and Plasma Volumes}

A dual tracer method ${ }^{32}$ was used to quantify the leakage rate (LR) of albumin from the circulation into the interstitial space of nude mouse ears at various times after local injection of adenoviral vectors $\left(1 \times 10^{8} \mathrm{PFU} / \mathrm{site}\right)$. LR is equivalent to the permeability-surface area product (PS, $\mu \mathrm{l} / \mathrm{min}-\mathrm{g}$ ). This method also allowed us to determine the intravascular volume of plasma at virus injection sites as a quantitative measure of the intensity of the angiogenic response.

Radioiodine-labeled bovine serum albumins ( ${ }^{125} \mathrm{I}$-BSA, specific activity $3.7 \mu C_{\mathrm{i}} / \mu \mathrm{g}$ and ${ }^{131} \mathrm{I}$-BSA, specific activity $72.5 \mu C_{\mathrm{i}} / \mu \mathrm{g}$, PerkinElmer Life
Sciences, Boston, MA, USA) were diluted in Hanks' balanced salt solution supplemented with $1 \mathrm{mg} / \mathrm{ml}$ unlabeled carrier BSA. Free iodine was $<5 \%$ as determined by trichloro-acetic acid precipitation. In all, $5 \mu C_{\mathrm{i}}$ of ${ }^{125} \mathrm{I}$-BSA $(0.1 \mathrm{ml})$ were injected i.v. via the tail vein into nude mice that had been weighed and anesthetized with Avertin (tribromoethanol, $200 \mathrm{mg} / \mathrm{kg}$ ). After $25 \mathrm{~min}$, animals received a second i.v. injection of $5 \mu C_{\mathrm{i}}$ of ${ }^{131} \mathrm{I}$-BSA $(0.1 \mathrm{ml})$ to provide a measure of intravascular tracer. At $5 \mathrm{~min}$ after the second injection, an aliquot of blood $(0.5 \mathrm{ml})$ was taken in heparin by cardiac puncture and animals were immediately euthanized by $\mathrm{CO}_{2}$ narcosis. Ears were removed by cauterization to prevent blood leakage. A central circular portion of each ear $\sim 8 \mathrm{~mm}$ in diameter corresponding to the site of adenoviral vector injection and containing the entire region of angiogenesis was dissected free and weighed. Plasma and tissue samples were subjected to gamma counting in a Wallac-LKB Model 1470 Wizard gamma counter that had been normalized to account for spillover of ${ }^{131} \mathrm{I}$ counts into the ${ }^{125} \mathrm{I}$ window and vice versa. Counts per gram of tissue for the ears and counts per microliter of plasma were used to calculate plasma volume, and albumin LR ( $\mu \mathrm{l} / \mathrm{min}-\mathrm{g}$ ), using the following equations: ${ }^{32}$

$$
\begin{gathered}
A_{131}=C_{\mathrm{p} 131} * V_{\mathrm{p}}+\mathrm{LR} * C_{\mathrm{p} 131} * 5 \\
A_{125}=C_{\mathrm{p} 125} * V_{\mathrm{p}}+\mathrm{LR} * C_{\mathrm{p} 125} * 30 \\
\mathrm{LR}=1 / 25 *\left(\mathrm{~A}_{125} / C_{\mathrm{p} 125}-A_{131} / C_{\mathrm{p} 131}\right) \\
V_{\mathrm{p}}=1 / 5 *\left(6 * \mathrm{~A}_{131} / C_{\mathrm{p} 131}-A_{125} / C_{\mathrm{p} 125}\right)
\end{gathered}
$$

where

$$
A=C_{\mathrm{p}} * V_{\mathrm{p}}+\mathrm{LR} * C_{\mathrm{p}} * t
$$

$A=$ total radioactivity of tissue $\left(\mu C_{\mathrm{i}} / \mathrm{g}\right) ; C_{\mathrm{p}}=$ concentration of radioactive tracer in plasma $\left(\mu C_{\mathrm{i}} / \mu \mathrm{l}\right)$; $V_{\mathrm{p}}=$ volume of plasma in tissue $(\mu \mathrm{l} / \mathrm{g}) ; \mathrm{LR}=$ leakage rate from plasma into tissue $(\mu \mathrm{l} / \mathrm{min}-\mathrm{g}) ; t=$ time elapsed since injection of tracer (min).

\section{Confocal Microscopy}

Mice were injected i.v. with $100 \mu \mathrm{l}$ of saline containing $1 \mathrm{mg}$ lysine-fixable FITC-labeled dextran (FITCD, $2 \times 10^{6} \mathrm{MW}$, Molecular Probes, Eugene, OR, USA). Ears were excised as above and fixed in cold $4 \%$ paraformaldehyde for $1 \mathrm{~h}$. The dorsal half of each ear was then gently separated from the underlying cartilage, which remained attached to the ventral half. Both halves were washed in PBS containing $2 \%$ sucrose for $30 \mathrm{~min}$, mounted in imaging chambers in Vectashield (Vector Laboratories, Burlingame, CA, USA). Whole mounts were visualized with a 1024 MRC Bio-RAD confocal microscope equipped with an Argon-Krypton laser. 
Five to seven fields were visualized using $\times 10-40$ objectives with a zoom factor of up to $\times 3$. Confocal $z$ sectioning $(z$ step $=0.2-0.5 \mu \mathrm{m}$ ) was used to collect stacks of optical sections that were processed using Bio-Rad LaserSharp version 3.2 software.

\section{Electron Microscopy}

Anionic ferritin (FE, cadmium-free, from horse spleen, Sigma Chemical Company, St Louis, MO, USA) was injected i.v. into adenoviral vector-treated mice via the tail vein at a dose of $0.5-1 \mathrm{mg} / \mathrm{g}$ body weight. FE is an iron-rich protein that is normally present in plasma at low concentrations and that provides a convenient tracer to follow macromolecular transport because individual FE molecules can be visualized directly by electron microscopy. Animals were euthanized 30 min later and the ears were fixed and processed as previously described, using either of two postfixation protocols: osmiumcollidine uranyl en bloc (OCUB) or potassium ferrocyanide-reduced osmium (OPF). ${ }^{33}$

\section{Statistics}

Data were analyzed by ANOVA, together with Dunnett's post hoc multiple comparisons test, or by nonparametric Kruskall-Wallis ANOVA, together with Dunn's post hoc multiple comparisons test.

\section{Results}

\section{Angiogenic Response Induced by Ad-VEGF-A ${ }^{164}$}

Ad-VEGF-A ${ }^{164}$ induced a dose-dependent angiogenic response that achieved maximal intensity at $1-2 \times 10^{8}$ PFU (Figure 1a and b). MV formed initially (1-5 days) and, from about day 7, evolved into GMP, vascular malformations and capillaries as previously described..$^{4,9,17,18,21,34}$ In addition, VEGFA also induced the formation of abnormal giant lymphatics. ${ }^{35}$ After 3-4 weeks, GMP began to devolve, and, by 2-3 months, overall microvascular density returned to near normal levels. However, vascular malformations (Figure 1b, 128 days) and giant lymphatics (not shown) persisted indefinitely. ${ }^{4,21,34}$

\section{Kinetics of VEGF-A ${ }^{164}$ mRNA and Protein Expression}

We performed quantitative real-time $\mathrm{PCR}^{30}$ and ELISA assays to correlate VEGF-A ${ }^{164}$ mRNA and protein expression levels with the angiogenic response (Figure 2). Following injection of $2 \times 10^{8} \mathrm{PFU}$ of Ad-VEGF-A ${ }^{164}$, high levels of VEGF-A ${ }^{164}$ mRNA were found on day 1 (nearly 1500 copies of VEGF$\mathrm{A}^{164}$ mRNA $/ 10^{6} 18 \mathrm{~S}$ rRNA) but these fell rapidly over a few days to much lower levels that remained detectable (though fewer than five copies $/ 10^{6}$ copies $18 \mathrm{~S}$ rRNA) at least through 36 days (Figure 2a). ELISA assays detected total VEGF-A ${ }^{164}$ protein a

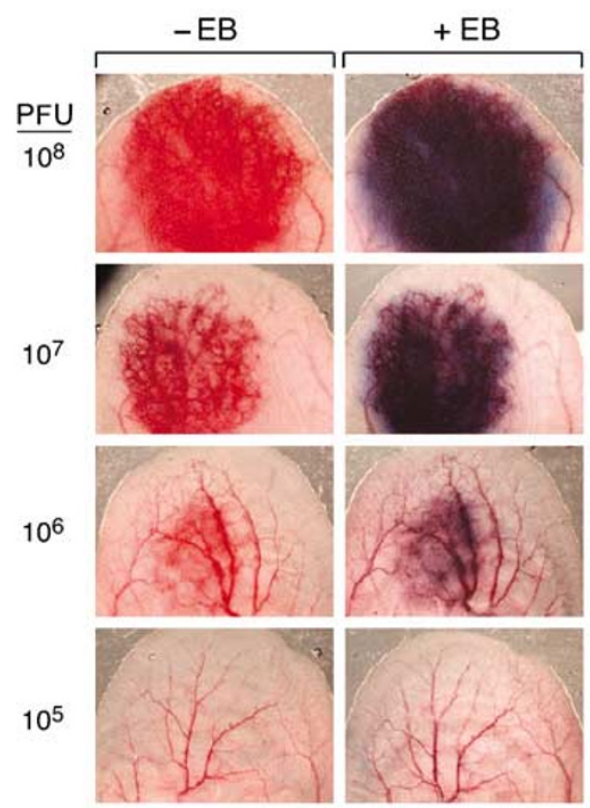

b

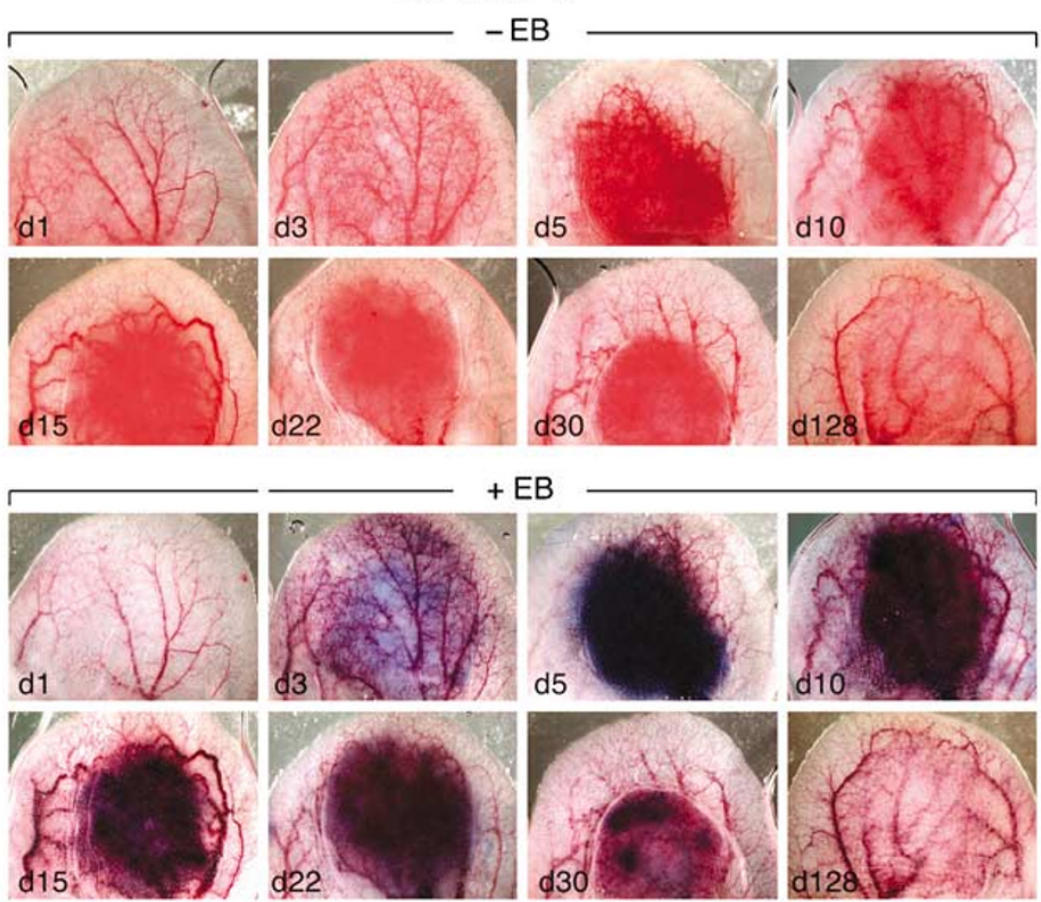

Figure 1 Angiogenic and permeability responses to Ad-VEGF-A ${ }^{164}$ in the ears of nude mice, typical of more than a dozen repetitions. (a) Dose response $\left(10^{5}-10^{8} \mathrm{PFU}\right.$ adenoviral vector) at 5 days. (b) Kinetics of the response over time from 1 to 128 days. Ears were photographed, Evans blue dye was injected i.v., and $30 \mathrm{~min}$ later ears were re-photographed to assess plasma protein leakage (+EB). 


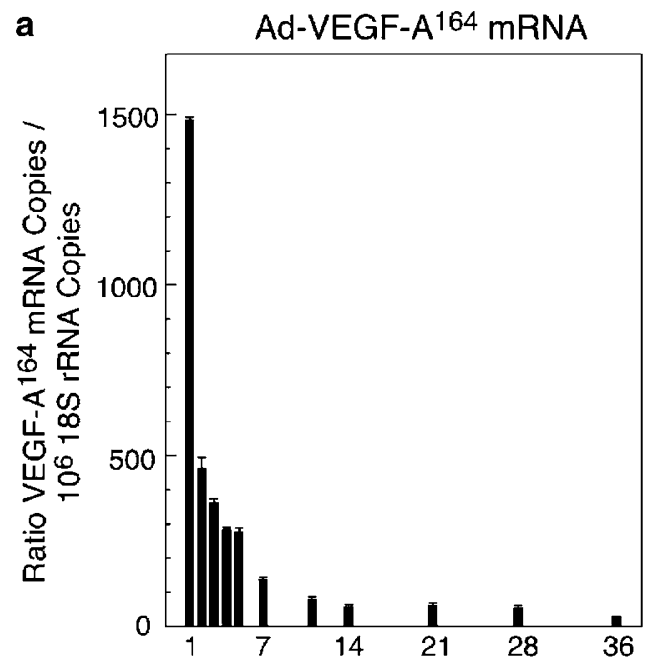

Days after Adenoviral Vector Injection

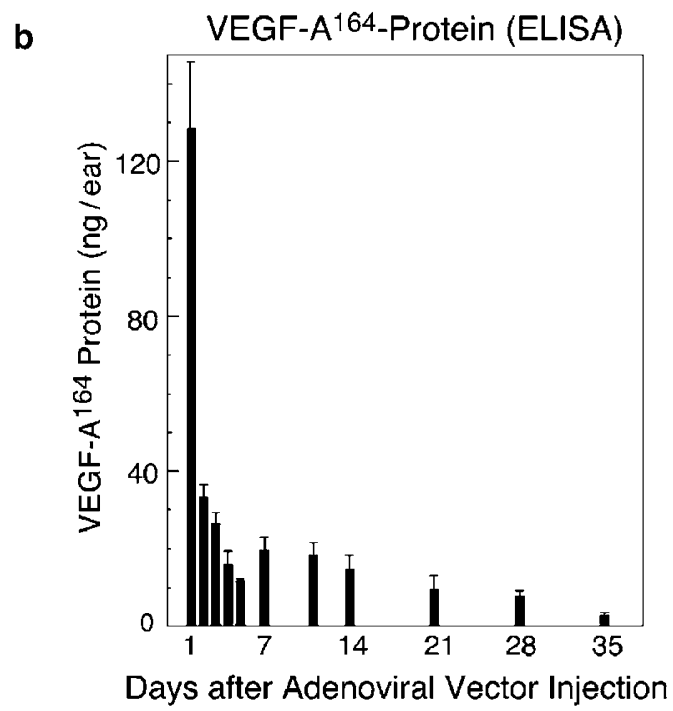

Figure 2 Expression levels of VEGF-A ${ }^{164}$ mRNA (a) and protein (b) in mouse ears at various times after injection of $2 \times 10^{8} \mathrm{PFU}$ of Ad-VEGF-A $A^{164}$. VEGF-A ${ }^{164}$ mRNA is expressed as a ratio of copies of VEGF-A ${ }^{164}$ mRNA per $10^{6}$ copies of $18 \mathrm{~S}$ rRNA. Each data point represents mean \pm s.e. from 3 to 6 ears.

levels of nearly $130 \mathrm{ng} / \mathrm{ear}$ (ie, per $8 \mathrm{~mm}$ punch biopsy) on day 1; like mRNA, VEGF-A ${ }^{164}$ protein levels declined exponentially over time, to $\sim 2 \mathrm{ng} /$ ear on day 35 . These levels of VEGF-A ${ }^{164}$ are comparable to those found in malignant tumors. ${ }^{5}$

\section{Quantitation of the Angiogenic Response}

We used a dual tracer method to determine intravascular plasma volumes (Vp, $\mu \mathrm{l}$ plasma/g tissue) at sites of adenoviral vector injection as a surrogate quantitative measure of the angiogenic response $^{32}$ (Figure 3). Intravascular volume rose dramatically over the first few days, in parallel with MV formation, peaking on day 5 at values $\sim 16$ times control levels. Thereafter, as MV evolved into GMP, capillaries and vascular malformations,

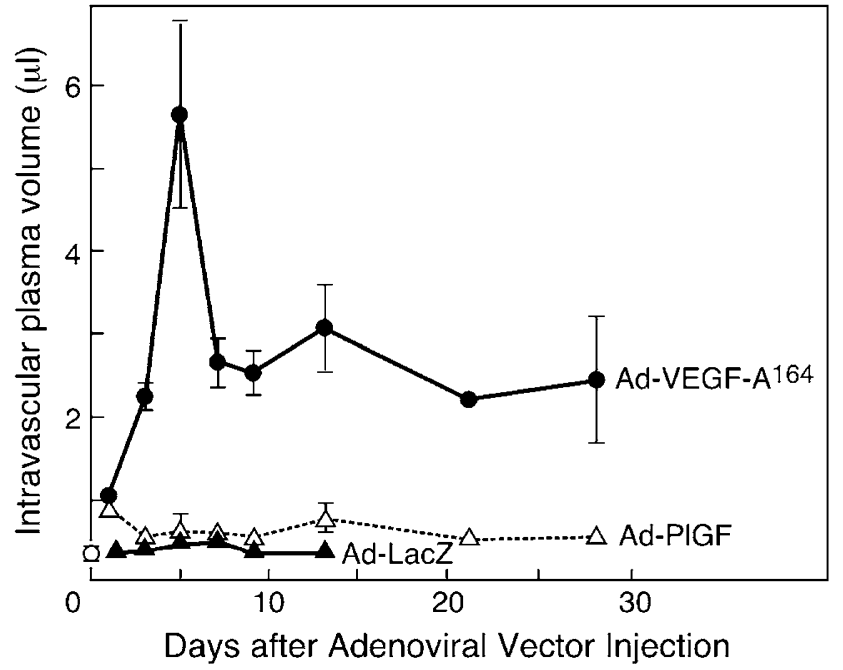

Figure 3 Intravascular plasma volume (mean \pm s.e.) as a quantitative measure of the angiogenic response. $8 \mathrm{~mm}$ punch biopsies (encompassing the entire reactions) were taken at indicated times after injection of $1 \times 10^{8} \mathrm{PFU}$ of Ad-VEGF-A ${ }^{164}$, Ad-PlGF or AdLacZ. Each point represents data from 3 to 6 ears. Clear circle at time zero represents plasma volume in $8 \mathrm{~mm}$ punch biopsies of uninjected control ears. Volumes in Ad-VEGF-A ${ }^{164}$ injected ears were significantly increased above uninjected control sites at all intervals except 1 day. Ad-PlGF- or Ad-LacZ-injected sites did not differ significantly from uninjected control sites at any time (analysis of variance and Dunnett's multiple comparisons test).

vascular volumes fell to lower but still significantly elevated plateau levels that remained elevated at more than two times those of control ears for at least 28 days. ${ }^{21,34}$ By contrast, vascular volumes did not increase detectably in ears injected with equivalent amounts of either Ad-PlGF or Ad-Lac-Z.

\section{Macromolecular Extravasation at Ad-VEGF-A ${ }^{164}$-Injected Sites}

The permeability status of the new blood vessels induced by Ad-VEGF-A ${ }^{164}$ was assessed initially by visual inspection following i.v. injection of Evan's Blue dye (Figure 1). This dye binds noncovalently to plasma proteins and therefore provides a visible measure of plasma protein leakage. Dye leakage was evident by 3 days after Ad-VEGF-A ${ }^{164}$ injection, reached a peak at 5 days, and declined gradually thereafter to very low levels at 30 days and beyond (Figure 1b). By contrast, comparable amounts of AdPlGF induced little or no dye leakage at any time (data not shown).

Quantitative measurements of plasma albumin leakage were performed with a dual tracer method. ${ }^{32}$ Significant radioactive albumin leakage was detected at Ad-VEGF-A ${ }^{164}$-injected sites but not at sites injected with equivalent amounts of either AdPlGF or Ad-Lac-Z (Figure 4). At Ad-VEGF-A ${ }^{164}$ injected sites, the leakage rate (LR) was significantly increased from days 3 to 13 (1.9-fold above uninjected control sites on day 3 and 3.5-fold on day 5 ), 
772

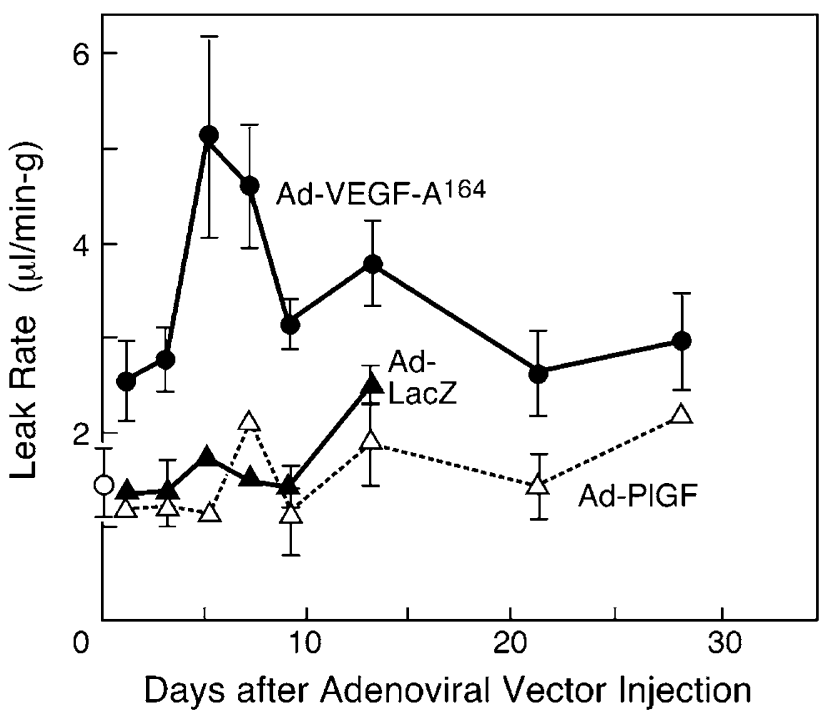

Figure 4 Leakage rate (LR, mean \pm s.e.) of radiolabeled albumin in mouse ears at various times following injection of $1 \times 10^{8} \mathrm{PFU}$ AdVEGF-A ${ }^{164}$, Ad-PlGF or Ad-Lac-Z, compared with uninjected control ears (clear circle at time zero). Leakage at Ad-VEGF-A ${ }^{164}$ injected sites ( $8 \mathrm{~mm}$ punch biopsies) was increased significantly or highly significantly above uninjected control ear sites on days 5-14. By contrast, LR did not increase significantly at any time at sites injected with Ad-PlGF or Ad-Lac-Z (analysis of variance and Dunnett's multiple comparisons test).

before declining toward lower but still elevated levels that persisted for at least a month.

\section{Leakage of FITC-Dextran from MV and GMP}

In order to identify the specific vessel types that were leaky, we injected lysine-fixable FITC-dextran (MW, 2 million) i.v. into mice at various times after ear injection of $1 \times 10^{8} \mathrm{PFU}$ of Ad-VEGF-A ${ }^{164}$. As early as 1 day confocal microscopy revealed extravasation of FITC-D from developing MV (Figure 5b) but leakage became much more extensive by day 4 as MV increased in number and size (Figure 5c). GMP formed subsequently and also leaked circulating FITC-dextran but to a lesser extent than MV (Figure $5 \mathrm{~d}$ and e). Vascular malformations and capillaries forming over the same interval did not leak (Figure 5f).

\section{Ultrastructure of MV and GMP}

MV formed from pre-existing venules by a process that involved breakdown of vascular basement membranes, detachment and resulting decreased coverage of pericytes, extensive (four- to five-fold) vessel enlargement, and extreme thinning of the lining endothelium ${ }^{17}$ (Figures 6 and 7; Table 1). Nuclei were often enlarged, displayed mitotic figures, and often projected into the vascular lumens. A characteristic feature of normal venular endothelium is the presence of vesiculo-vacuolar organelles (VVOs), chains of uncoated, intercon- nected vesicles and vacuoles that span the endothelial cytoplasm from lumen to albumen; VVOs have been shown to provide a pathway for macromolecular leakage in response to VEGF-A and other vascular permeabilizing agents ${ }^{20,23,36}$ (Figure 6a and b). Based on ultrastructural analysis of 34 normal venular endothelial cells, VVOs were found to occupy $17.9 \pm 0.9 \%$ (mean \pm s.e.) of the cytoplasm, excluding nuclei. Also, the membranes enveloping VVO vesicles and vacuoles were found to be extensive, measuring $2.25 \pm 0.08$ times that of the plasma membrane of these cells.

VVOs underwent extensive structural changes in the course of MV formation. As the endothelium thinned, VVOs decreased significantly in both frequency and complexity (Figures 6c, d and 7; Table 2). Mean VVO frequency declined almost two-fold from $0.74 /$ linear $\mu \mathrm{m}$ in control ear postcapillary venular endothelium to $0.38 /$ linear $\mu \mathrm{m}$ in MV at 3 days; the number of vesicles and vacuoles per individual VVO declined similarly from 11.38 to 5.85 . As a result, total numbers of VVO-associated vesicles and vacuoles declined nearly four-fold by day 3 (from 8.20 to 2.24 per linear $\mu \mathrm{m}$ ). Some uncoated vesicles and vacuoles in endothelial cell cytoplasm could not be positively assigned to VVOs, either because they were not interconnected in the plane of section or because they were in fact isolated structures (eg, caveolae); these also declined significantly between days 0 and 3. Overall, therefore, total uncoated cytoplasmic vesicles and vacuoles decreased from 11.04/linear $\mu \mathrm{m}$ in the endothelium of normal venules to 3.94/ linear $\mu \mathrm{m}$ in MV endothelium on day 3. As a result of these changes, thinned MV endothelium was commonly spanned by only a few or even a single residual vesicle (Figure $7 \mathrm{~d}-\mathrm{f}$ ). In other instances, the endothelium displayed deep invaginations that proceeded from either the lumen or ablumen and progressed nearly to the opposing plasma membrane (Figure $7 \mathrm{f}$ and g). In addition, a small fraction $(0.20 \%$ on day 3$)$ of MV surface area was fenestrated (curved arrows, Figure $7 d$, g and i; Table 2).

MV evolved into GMP (Figure 8), as well as into capillaries and vascular malformations. ${ }^{4,34}$ The endothelial cells lining GMP were extremely thin and contained even fewer cytoplasmic vesicles and vacuoles than MV; however, fenestrae were more abundant, covering $1.5 \%$ of the endothelial cell surface area at 15 days (Table 2). Openings in GMP vascular endothelium that allowed direct communications between the vascular lumen and ablumen were extremely rare at all times studied (only 1 was observed in the course of examining 2538.5 linear $\mu \mathrm{m}$ of MV and GMP endothelial cell perimeter, Table 2).

\section{Pathways of Macromolecule Extravasation from MV and GMP}

We used transmission electron microscopy to determine the anatomic pathways by which a large 

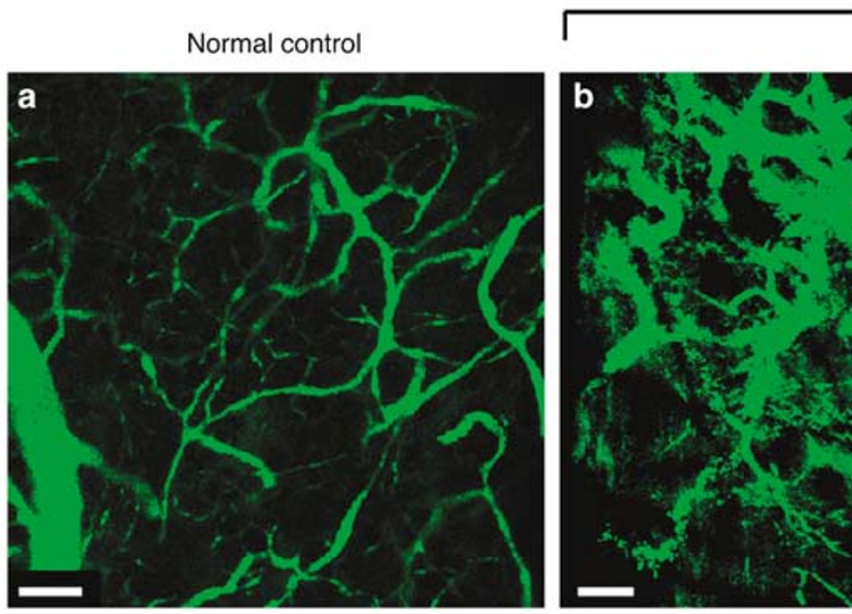

Mother vessels
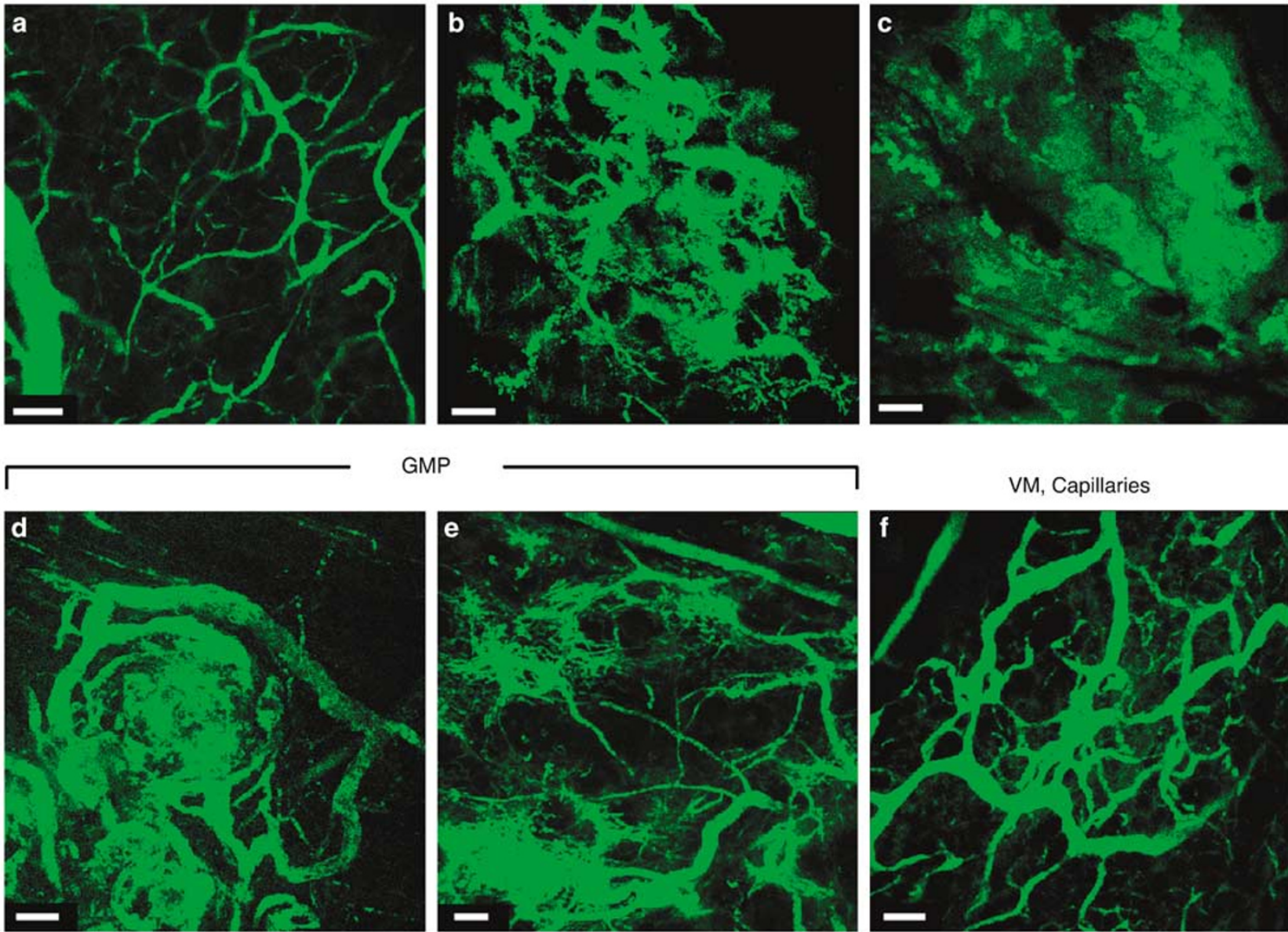

GMP
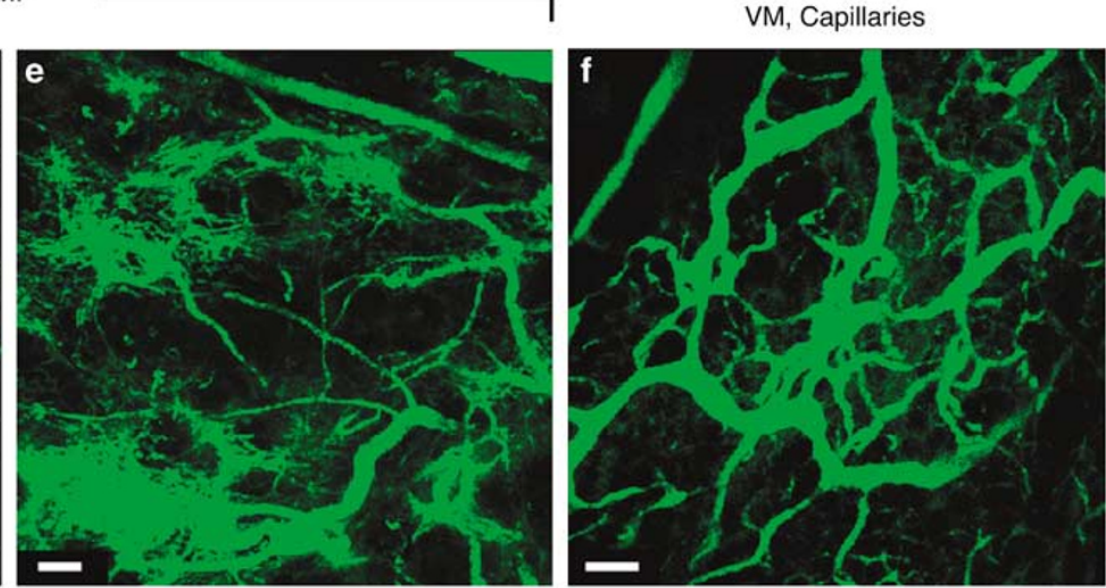

Figure 5 Confocal microscopy $30 \mathrm{~min}$ after i.v. injection of $2 \times 10^{6} \mathrm{kDa}$ lysine fixable FITC-D at various times following injection of $1 \times 10^{8} \mathrm{PFU}$ of Ad-VEGF-A ${ }^{164}$. (a) Normal, uninjected control ears did not exhibit vascular leakage. (b, c) MV exhibited focal leakage on day 1 (b) and extensive leakage at 4 days (c) after Ad-VEGF-A ${ }^{164}$. (d, e) GMP with moderate leakage of FITC-D, days 21 and 28, respectively. (f) Vascular malformations (VM, large vessels) and capillaries (smallest vessels) did not leak FITC-D. Bars $=100 \mu \mathrm{m}$.

protein tracer, ferritin (FE), extravasated from MV and GMP (Figures 7 and 8; Table 3). In normal venular endothelium the concentration of FE in the VVOs was $4.26 \%$ of that in plasma whereas FE in the subendothelial space was $<0.1 \%$ of the FE concentration in plasma, consistent with very low levels of tracer extravasation. In MV, much higher FE concentrations were found in both VVOs (17$19 \%$ of plasma concentration) and in the subjacent extravascular space $(5 \%$ to nearly $10 \%$ of plasma concentration) (Figure 7; Table 3). These data provide strong evidence that MV are highly permeable to FE and further that VVOs are a prominent anatomic pathway for tracer extravasation. Numerous FE molecules were also found subjacent to areas of endothelial cell fenestration (Figure 7i). Endothelial junctions remained closed and the intercellular cleft did not widen to accommodate FE particles (Figure 7f).

GMP also leaked FE but to a lesser extent than MV (Figure 8, Table 3). Residual VVO vesicles and/or caveolae often contained FE and, along with fenestrae, provided a transcellular pathway for FE extravasation (Figure 8c and d). As GMP matured, tracer leakage declined, persisting but only at low levels at 21 days (Table 3).

\section{Discussion}

Adenoviral vectors engineered to express VEGF-A ${ }^{164}$ induce an angiogenic response that generates several types of new and morphologically distinct blood vessels., ${ }^{4,21}$ MV formed initially and achieved maximal size and frequency at $\sim 5$ days. MV then evolved into capillaries by trans-luminal bridging (Figure 6d) and into other types of daughter vessels, including GMP and arterio-venous-like vascular malformations by processes that have been previously described. ${ }^{4,34}$ Vessels of each of these types are common in malignant tumors. ${ }^{14} \mathrm{MV}$ are also found in healing wounds and chronic inflammation, states that, like tumors, are characterized by overexpression of VEGF-A, angiogenesis and vascu- 

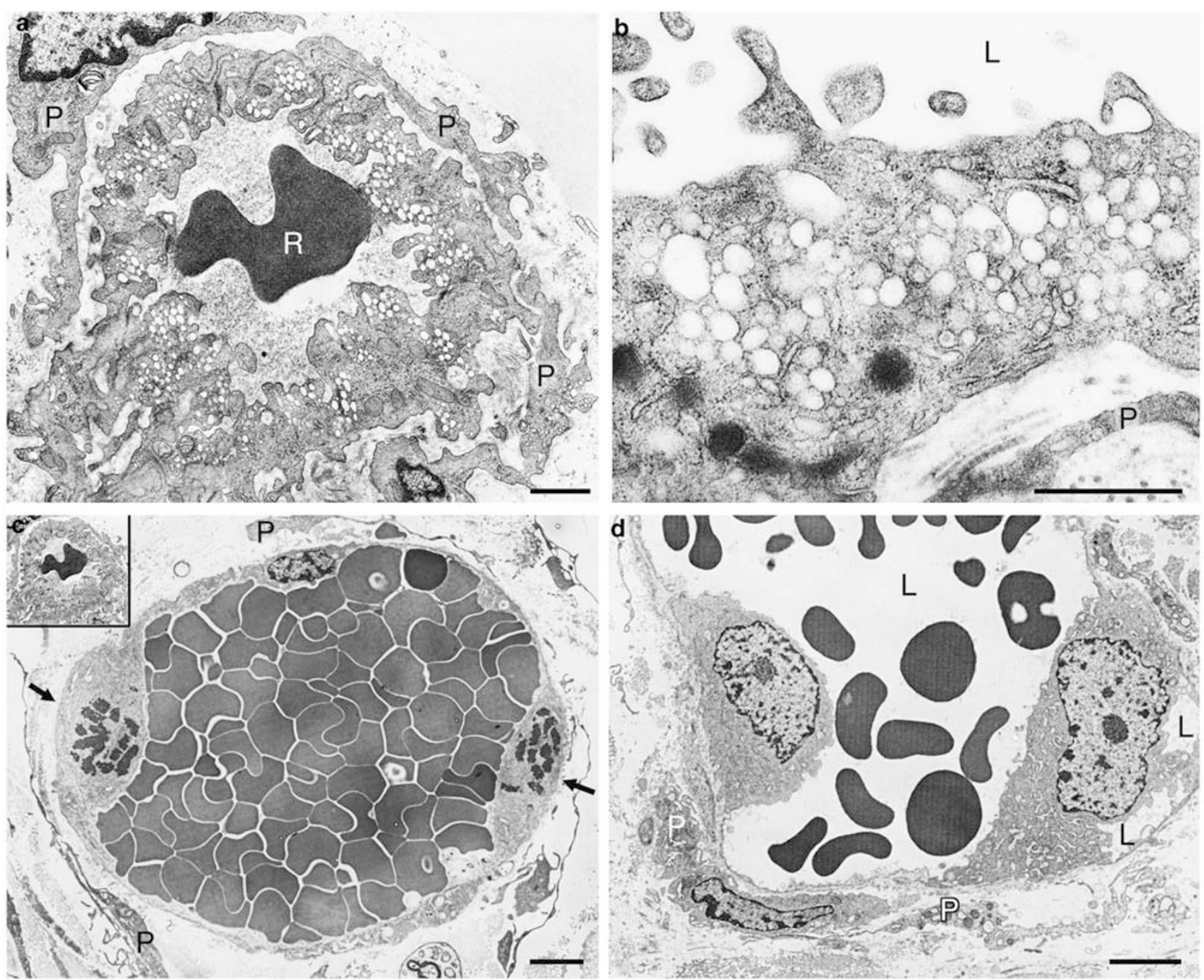

Figure 6 Transmission electron micrographs of control ear venules $(\mathbf{a}, \mathbf{b})$ and of MV (c, d) 3 days after local injection of Ad-VEGF-A ${ }^{164}$. (a, b) Typical normal venules lined by cuboidal endothelium. The cytoplasm contains prominent VVOs and is enveloped by a complete coating of pericytes (P), R, red blood cell. (c, d) Typical MV are greatly enlarged vascular structures, characterized by extensive endothelial cell thinning; striking reduction in VVOs and other cytoplasmic vesicles; prominent nuclei that project into the vascular lumen; frequent mitotic figures (arrows, c); endothelial cell bridging with the formation of multiple lumens (L, d) ${ }^{9}$; and decreased pericyte (P) coverage. Note that the MV lumen (c) is packed with red blood cells, indicative of extensive plasma extravasation. Inset: the normal venule depicted in (a) is reproduced in (c) at the same magnification as the MV to illustrate differences in relative size of normal venules and MV. OCUB processing. Scale bars: (a, b) $1 \mu \mathrm{m}$; (c, d) $5 \mu \mathrm{m}$.

lar hyperpermeability. ${ }^{2,14,37-39}$ Therefore, adenoviral vectors expressing VEGF-A ${ }^{164}$ provide a practical means for generating large numbers of surrogate blood vessels of the types found in pathological angiogenesis.

The present study was undertaken to investigate the permeability status of each of these vessel types and to elucidate the pathways by which macromolecules extravasated from them. Evan's blue dye was used initially to assess overall plasma protein leakage at successive stages of angiogenesis. ${ }^{40}$ Dye extravasation first became evident at 3 days after Ad-VEGF-A ${ }^{164}$ injection; reached maximal intensity at around day 5; persisted at a high level through day 15; and, thereafter, gradually declined toward normal low levels (Figure 1). Quantitative data consistent with these findings were obtained with a dual radioactive tracer method that assessed the intensity of the angiogenic response (Figure 3) as well as the leakage rate of plasma albumin (LR, Figure 4). LR increased significantly on day 3, reached a peak on day 5 , and then declined to plateau values that remained statistically elevated at least through day 13. Neither Evan's blue extravasation nor LR increased detectably at any time at sites injected with comparable doses of Ad-LacZ or AdPlGF, though PlGF expression levels and kinetics were similar to those induced by Ad-VEGF-A ${ }^{164}$ (data not shown).

The kinetics of new blood vessel formation and increased vascular permeability suggested that MV and at least some daughter vessels were leaky. 

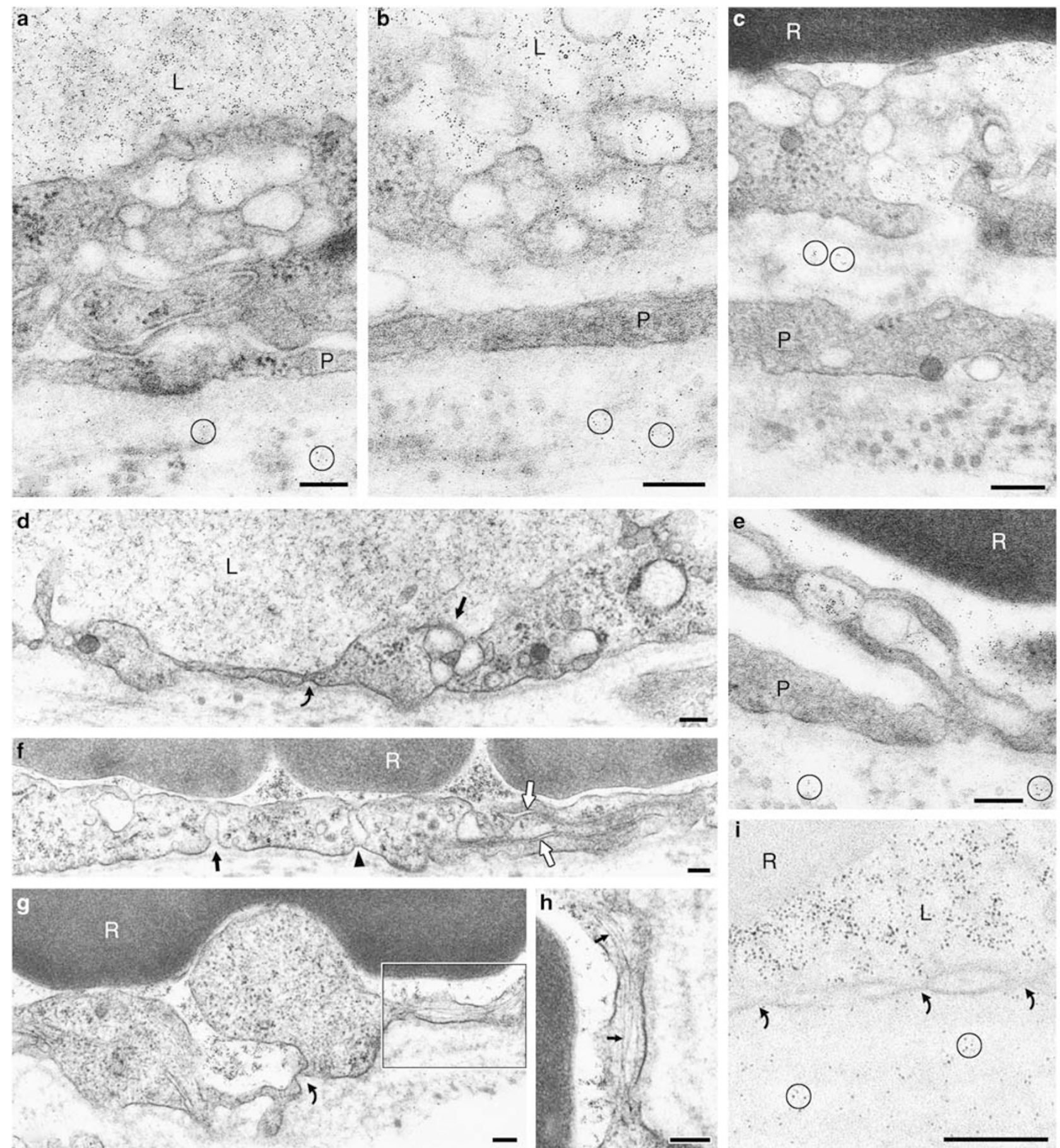

Figure 7 Electron micrographs of MV endothelial cells at 1-5 days after local injection of Ad-VEGF-A ${ }^{164}$ and 30 min after i.v. injection of FE. (a-c) Thinned endothelium with FE (dark black particles) in vascular lumens (L), in VVO vesicles/vacuoles, and extravasated into the extravascular space. (d-i) MV endothelium is extremely thinned and spanned by no more than 1-3 vesicles/vacuoles (eg, straight arrow in d), most of which contain FE. Cytoplasm is also marked by deep invaginations (straight arrow in f). In ( $(\mathbf{g})$, boxed area shows microtubules oriented in direction of endothelial cell thinning; better seen at higher magnification in (h) (arrows). Intercellular clefts of adjacent MV endothelial cells (white arrows) (f) are not widened and do not admit FE. Fenestrae (curved arrows in d, g, i) occupied a small but significantly increased fraction of the surface area and provided a second trans-endothelial cell route for FE extravasation (i). To facilitate viewing, some clusters of extravasated FE particles are encircled in (a-c, e and i). L, lumen; P, pericytes; R, red blood cells. OCUB processing except (i), OPF method. Scale bars: $200 \mathrm{~nm}$.

Confocal microscopy was used to test this hypothesis and confirmed that MV, and to a lesser extent GMP, leaked high molecular weight FITC-D; however, other daughter vessels such as capillaries and vascular malformations did not (Figure 5). Transmission electron microscopy (TEM) confirmed 
Table 1 Thinning of vascular endothelium in the course of mother vessel formation following ear injection of $2 \times 10^{8} \mathrm{PFU}$ Ad-VEGF-A ${ }^{164}$ a

\begin{tabular}{lccc}
\hline Vessel type & $\begin{array}{c}\text { Days after Ad- } \\
\text { VEGF-A } A^{164} \\
\text { injection }\end{array}$ & $\begin{array}{c}\text { Number of } \\
\text { measurements }\end{array}$ & $\begin{array}{c}\text { Endothelial cell } \\
\text { height (mean } \\
\mu m \pm s . e .)\end{array}$ \\
\hline Normal venules & 0 & 179 & $1.43 \pm 0.05$ \\
Mother vessels & 1 & 187 & $0.89 \pm 0.04^{\mathrm{b}}$ \\
& 3 & 187 & $0.65 \pm 0.03^{\mathrm{b}}$
\end{tabular}

${ }^{a}$ Endothelial cell height was measured in normal postcapillary venules or in mother vessels in sections in which the plane of section was at right angles to the vessel. Areas involving nuclei were excluded.

${ }^{\mathrm{b}}$ Highly significantly different from normal postcapillary venule endothelium $(P<0.001$ by nonparametric Kruskall-Wallis ANOVA and Dunn's post hoc multiple comparison test).

these confocal findings with another tracer, ferritin (FE).

TEM also allowed us to elucidate the anatomic pathways by which FE traversed MV and GMP (Table 3; Figures 6-8). FE extravasated from both MV and GMP by trans-endothelial cell pathways involving VVOs and fenestrae (Table 3; Figures 6-8). Increased FE extravasation was characterized by parallel increases of FE within VVOs and in the immediate subendothelial space. In normal venular endothelium the concentration of FE in VVOs and subendothelial space was, respectively, 4.26 and $0.09 \%$ of that in plasma. By contrast, FE concentration in MV endothelial cell VVOs (days 1-6) was increased $\sim$ four-fold to $16.7-19 \%$ of that in plasma and the FE concentration immediately outside MV was increased 58-110-fold to $5.2-9.9 \%$ of that in plasma. In GMP (days 8-21), FE concentration in both VVOs and the subendothelial space was increased 1.5-3.7-fold to a concentration of 6.5$15.8 \%$ of that of plasma in VVOs and to a concentration of $0.4-4.4 \%$ of plasma in the subendothelium (Table 3). We found no evidence for FE extravasation by an interendothelial cell route. Junctions between endothelial cells were invariably closed, interendothelial clefts were not widened, and neither admitted FE (particle size, $11 \mathrm{~nm}$ ). We cannot of course rule out the possibility of rare openings through the endothelium that escaped our notice because of insufficient sampling. However, in our survey of 2313 linear $\mu \mathrm{m}$ of MV and GMP endothelium, we encountered only a single such opening (Table 2) and could not determine whether it was trans-endothelial ${ }^{41,42}$ or interendothelial. ${ }^{25}$

Taken together, the confocal and electron microscopic data indicated that only a subset of VEGF$\mathrm{A}^{164}$-induced vessels leaked, MV (predominantly) and GMP. Therefore, measures of overall vascular leakage such as LR, which provide a combined average of extravasation from leaky and nonleaky vessels, inevitably underestimate the permeability

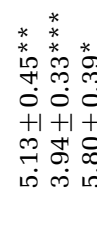

**** ${ }^{*} \stackrel{*}{*}$

กั $\stackrel{*}{*}$ 은

0
0
+1

No⿱

공

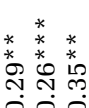

000

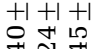

लं

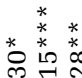

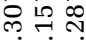

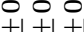

象 10

ते

*

$2^{*}+$

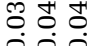

00

舟

$\circ \dot{0} 0$

000

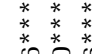

ํำ 0000 1
0
0 -

$* * *$

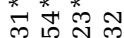
0000 ㄴํㄴ เ

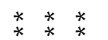

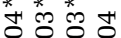
0000

$+1+1+1+$

ㄱํㅅำ 잉

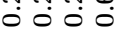

0400

$\stackrel{8}{\circ}$

00

$+1+1+$

००००

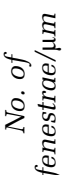

(1)

\%ั 5.5

$\begin{array}{lll}0 & 0 & 0 \\ +1 & +1 & +1\end{array}$

กั

$\circ 00$

ब

$m$
$m$
$m$

ก $\infty$ เ $\sigma$

会芦品品

$\frac{n}{\square}$

$\frac{\infty}{d}$

z

궁

$+1+1+1$

స్ ભ

o० 0 -

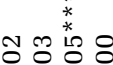

0 icio

능 웡

0.0ं

Tं

可䒬

है

政的。

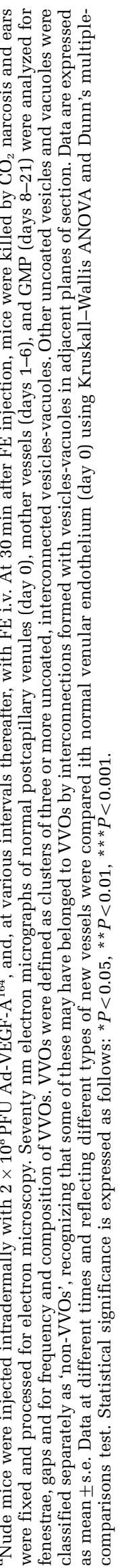



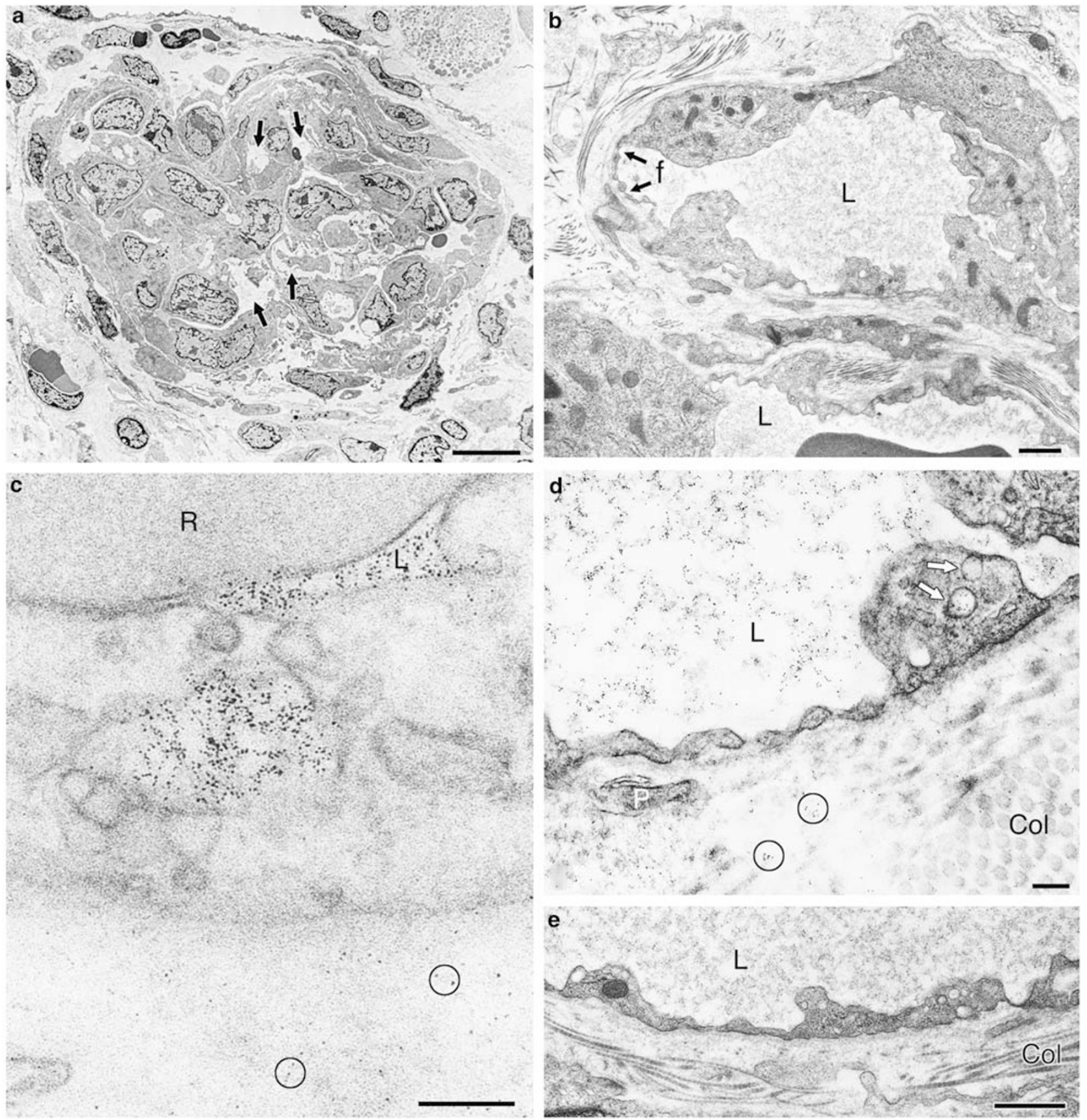

Figure 8 Electron micrographs of GMP at 10-15 days after ear injection of Ad-VEGF-A ${ }^{164}$ and 30 min after i.v. injection of FE. (a) Overview of a typical GMP; arrows indicate reduplicated basal lamina. (b) Higher magnification illustrates two small vascular lumens; note irregular endothelial cell thinning and fenestrations (f, arrows). (c) FE in vascular lumen, in residual VVO vesicles, and extravasated into the subendothelial space. (d, e) Extensively thinned and fenestrated endothelium with occasional residual FE-containing vesicles (white arrows, d). col, increased sub-basal lamina collagen. To facilitate viewing, some clusters of extravasated FE particles are encircled in (c and d). L, vascular lumens; R, red blood cell. OCUB processing except (c), OPF method. Scale bars: (a) $10 \mu \mathrm{m}$; (b, e) $1 \mu \mathrm{m}$; (c, d) $200 \mathrm{~nm}$.

of individual MV or GMP. Small numbers of developing MV had begun to leak FITC-D and FE as early as 1 day after administration of Ad-VEGF$\mathrm{A}^{164}$. However, such tracer extravasation was insufficient to generate a detectable increase in overall leakage as determined by LR or Evan's blue dye accumulation, presumably because of efficient lym- phatic clearance and the relative insensitivity of methodologies that measure average tracer extravasation. It is likely that similar considerations apply to tumors. Permeability of tumor vessels has been estimated to be four to 10 times that of normal tissues but the data are based on measurements of overall protein leakage that, like the LR measured 
Table 3 Concentration of ferritin (FE) in microvascular plasma, endothelial cell VVOs, and immediately subjacent extravascular (subendothelial) space in nude mouse ear skin at various times following injection of $2 \times 10^{8}$ PFU Ad-VEGF-A ${ }^{164 a}$

\begin{tabular}{|c|c|c|c|c|c|c|}
\hline \multirow{2}{*}{$\begin{array}{l}\text { Days after Ad-VEGF- } \\
A^{164} \text { injection }\end{array}$} & \multirow[t]{2}{*}{ Vessel type } & \multicolumn{3}{|c|}{ FE concentration (mean no. particles $/ \mu m^{2}$ ) } & \multicolumn{2}{|c|}{$\%$ Of luminal plasma concentratior } \\
\hline & & Luminal plasma & VVOs & $\begin{array}{l}\text { Subendothelial } \\
\text { space }\end{array}$ & VVOs & $\begin{array}{l}\text { Subendothelial } \\
\text { space }\end{array}$ \\
\hline 0 & Normal venules & 571 & 24.13 & 0.5 & 4.26 & 0.09 \\
\hline 1 & Mother vessels & 577 & 109.43 & 54.63 & $18.99 * * *$ & $9.92 * * *$ \\
\hline 3 & & 572 & 95.47 & 30.22 & $16.71^{* * *}$ & $5.24 * * *$ \\
\hline 6 & & 559 & 94.92 & 32.2 & $16.80 * * *$ & $5.75^{* * *}$ \\
\hline 8 & GMP & 567 & 86.24 & 24.74 & $15.77^{*}$ & $4.43^{* * *}$ \\
\hline 10 & & 569 & 79 & 14.03 & $14.59^{*}$ & $2.50 * * *$ \\
\hline 15 & & 555 & 58.22 & 5.89 & 10.82 & 1.13 \\
\hline 21 & & 588 & 37.67 & 2.47 & 6.48 & 0.43 \\
\hline
\end{tabular}

${ }^{\mathrm{a}}$ Mice were injected and tissues processed for electron microscopy as in Table 2. A total of 148 microvessels and 8338 VVO vesicles and vacuoles were analyzed. FE molecules were counted and their concentration (number of FE molecules/ $\mu \mathrm{m}^{2}$ ) was calculated in luminal plasma, in VVO vesicles and vacuoles, and in the underlying subendothelial space (up to $100 \mathrm{~nm}$ subjacent to the endothelial cell ablumen). Statistical differences between experimental groups and control (normal venular endothelium, day 0) were calculated with nonparametric Kruskall-Wallis ANOVA and Dunn's multiple-comparisons test. Statistical significance was expressed as follows: ${ }^{*} P<0.05,{ }^{*} * *<0.001$.

here, represent an average of leaky and nonleaky vessels..$^{2,5,43}$

Our data raise two additional issues. The first relates to the unexpected finding that vascular leakage did not correlate closely with local VEGF$\mathrm{A}^{164}$ mRNA or protein concentration. Local VEGF$\mathrm{A}^{164}$ protein levels were highest $(\sim 130 \mathrm{ng} / \mathrm{ear})$ at 1 day after Ad-VEGF-A ${ }^{164}$ injection and thereafter fell exponentially to much lower levels (Figure 2). However, overall vascular permeability, as measured by Evan's blue dye extravasation (Figure 1) or by LR (Figure 4), did not become significant until 3 days after adenoviral vector injection when VEGF-A ${ }^{164}$ protein levels were four-fold lower ( $<30 \mathrm{ng} / \mathrm{ear}$ ); such low levels of VEGF-A ${ }^{164 / 5}$ protein are barely sufficient to induce dye leakage when injected into normal mouse skin as a single bolus (our unpublished data). That overall permeability was not increased on day 1 was perplexing because single injections of VEGF-A ${ }^{165}$ protein of comparable and indeed much larger amounts (up to $800 \mathrm{ng}$ ) into normal mouse skin induce extensive extravasation of Evan's blue dye. A likely explanation for this finding is that continuous exposure of vessels to VEGF-A $^{164}$ over a period of hours, as occurs following Ad-VEGF-A ${ }^{164}$ injection, resulted in tachyphylaxis, that is, loss of vascular sensitivity to VEGF-A ${ }^{164}$ ligand. This may have resulted from such factors as downregulation or depletion of VEGF-A receptors. ${ }^{44,45}$ Nevertheless, although permeability responsiveness was diminished in the short-term, continuous exposure to VEGF-A ${ }^{164}$ initiated an angiogenic program that over a matter of days generated the formation of MV and GMP that were highly permeable to macromolecular tracers. It is noteworthy that these newly induced, hyperpermeable vessels strongly overexpressed both VEGFR-1 and VEGFR-2. ${ }^{17}$
A second related issue concerns our finding that, although VVOs provided an anatomic pathway by which substantial amounts of FE extravasated from MV and GMP, VVOs were significantly fewer in these neovessels than in normal venular endothelium (Figures 6 and 7; Tables 2 and 3). At least a partial answer to this paradox is suggested by the extensive endothelial cell thinning characteristic of both MV and GMP and the accompanying reduction in the complexity of the VVOs that remained. As a result, the trans-endothelial cell pathway for tracer passage was greatly shortened. Normal venules are lined by relatively cuboidal endothelial cells. Therefore, to pass from the vascular lumen to the ablumen, tracers must make their way through a stack of eight to 10 or more individual VVO vesicles and vacuoles. By contrast, in MV and GMP, tracers could extravasate by passing through only a few, often only one or two, vesicles and vacuoles (Figures 6-8; Table 1).

Unresolved by our data are the mechanisms by which VEGF-A ${ }^{164}$ opens VVOs to the passage of macromolecules, whether in MV and GMP or in normal venular endothelium. VVO vesicles and vacuoles are separated from each other and from the luminal and abluminal plasma membranes by diaphragms that, when closed, serve as barriers to tracer passage. ${ }^{16,20,23,24,26,36}$ The composition and function of these diaphragms is only now beginning to be understood, ${ }^{46,47}$ but it is thought that they serve as gates, preventing tracer passage unless they are opened by the action of VEGF-A or other vasoactive mediators. For molecules to traverse endothelium through VVOs, therefore, the diaphragms separating each of these interconnections must open to allow tracer passage.

Finally, our data suggest that VVOs have another function in addition to that of providing a conduit 
for macromolecule extravasation. In normal venular endothelium, VVOs constitute a large store of intracellular membrane, equivalent to more than twice that measured in the plasma membrane. Also, VVO membranes have properties in common with plasma membrane, such as expression of VEGFR-2 and CD31. ${ }^{48,49}$ As they form in response to AdVEGF-A ${ }^{164}$, MV acquire a $\sim$ two-fold increase in circumference and a $\sim$ four- to five-fold increase in cross-sectional area (Figure 6$)^{17}$; in parallel, the number of VVO vesicles and vacuoles/linear $\mu \mathrm{m}$ fell from 8.2 to $\sim 3$ (Table 2). Therefore, we suggest that VVOs provide a reservoir of membrane that can be incorporated into the plasma membrane to allow the rapid increases in vessel size associated with MV formation. These findings likely apply to the similar large, thin-walled MV that are found in tumors, healing wounds and chronic inflammatory states. ${ }^{37-39}$

\section{Acknowledgements}

This work was supported by US Public Health Service Grants HL-64402 and P01 CA92644 (HFD); AI-33372 and AI-44066 (AMD); and by a contract from the National Foundation for Cancer Research (HFD). We gratefully acknowledge the technical assistance of Susan H Bliss, Isabelle A Eckelhoefer, Kathryn Pyne and Steve Moskowitz.

\section{References}

1 Senger DR, Van de Water L, Brown LF, et al. Vascular permeability factor (VPF, VEGF) in tumor biology. Cancer Metastasis Rev 1993;12:303-324.

2 Brown LF, Detmar M, Claffey $\mathrm{K}$, et al. Vascular permeability factor/vascular endothelial growth factor: a multifunctional angiogenic cytokine. Exs 1997;79: 233-269.

3 Dvorak HF, Nagy JA, Feng D, et al. Vascular permeability factor/vascular endothelial growth factor and the significance of microvascular hyperpermeability in angiogenesis. Curr Top Microbiol Immunol 1999;237: 97-132.

4 Dvorak HF. How tumors make bad blood vessels and stroma. Am J Pathol 2003;162:1747-1757.

5 Dvorak HF. Vascular permeability factor/vascular endothelial growth factor: a critical cytokine in tumor angiogenesis and a potential target for diagnosis and therapy. J Clin Oncol 2002;20:4368-4380.

6 Dvorak HF. Tumors: Wounds that do not heal. Similarities between tumor stroma generation and wound healing. N Engl J Med 1986;315:1650-1659.

7 Nagy JA, Masse EM, Herzberg KT, et al. Pathogenesis of ascites tumor growth: vascular permeability factor, vascular hyperpermeability, and ascites fluid accumulation. Cancer Res 1995;55:360-368.

8 Nagy JA, Meyers MS, Masse EM, et al. Pathogenesis of ascites tumor growth: fibrinogen influx and fibrin accumulation in tissues lining the peritoneal cavity. Cancer Res 1995;55:369-375.
9 Nagy JA, Morgan ES, Herzberg KT, et al. Pathogenesis of ascites tumor growth: angiogenesis, vascular remodeling, and stroma formation in the peritoneal lining. Cancer Res 1995;55:376-385.

10 Dvorak H, Nagy J, Feng D, et al. Tumor architecture and targeted delivery. In: Abrams P, Fritzberg A (eds). Radioimmunotherapy of Cancer. Marcel Dekker, Inc.: New York, 2000, pp 107-135.

11 Carmeliet P, Moons L, Luttun A, et al. Synergism between vascular endothelial growth factor and placental growth factor contributes to angiogenesis and plasma extravasation in pathological conditions. Nat Med 2001;7:575-583.

12 Luttun A, Tjwa M, Moons L, et al. Revascularization of ischemic tissues by plgf treatment, and inhibition of tumor angiogenesis, arthritis and atherosclerosis by anti-flt1. Nat Med 2002;8:831-840.

13 Dvorak HF, Nagy JA, Dvorak AM. Structure of solid tumors and their vasculature: implications for therapy with monoclonal antibodies. Cancer Cells 1991;3:77-85.

14 Dvorak H. Tumor blood vessels. In: Aird W (ed). The Endothelium: A Comprehensive Reference. Cambridge University Press: Cambridge, 2006, in press.

15 Paku S, Paweletz N. First steps of tumor-related angiogenesis. Lab Invest 1991;65:334-346.

16 Feng D, Nagy JA, Dvorak AM, et al. Different pathways of macromolecule extravasation from hyperpermeable tumor vessels. Microvasc Res 2000;59:24-37.

17 Pettersson A, Nagy JA, Brown LF, et al. Heterogeneity of the angiogenic response induced in different normal adult tissues by vascular permeability factor/vascular endothelial growth factor. Lab Invest 2000;80:99-115.

18 Sundberg C, Nagy JA, Brown LF, et al. Glomeruloid microvascular proliferation follows adenoviral vascular permeability factor/vascular endothelial growth factor-164 gene delivery. Am J Pathol 2001;158: 1145-1160.

19 Goffin JR, Straume O, Chappuis PO, et al. Glomeruloid microvascular proliferation is associated with p53 expression, germline brca1 mutations and an adverse outcome following breast cancer. Br J Cancer 2003;89: 1031-1034.

20 Kohn S, Nagy JA, Dvorak HF, et al. Pathways of macromolecular tracer transport across venules and small veins. Structural basis for the hyperpermeability of tumor blood vessels. Lab Invest 1992;67:596-607.

21 Nagy JA, Vasile E, Feng D, et al. VEGF-A induces angiogenesis, arteriogenesis, lymphangiogenesis and vascular malformations. Cold Spring Harbor Symposium on Quantitative Biology 2002;LXVII:227-237.

22 Majno G, Gilmore V, Leventhal M. On the mechanism of vascular leakage caused by histamine type mediators. A microscopic study in vivo. Circ Res 1967;21: 833-847.

23 Feng D, Nagy JA, Hipp J, et al. Vesiculo-vacuolar organelles and the regulation of venule permeability to macromolecules by vascular permeability factor, histamine, and serotonin. J Exp Med 1996;183:1981-1986.

24 Feng D, Nagy JA, Pyne K, et al. Pathways of macromolecular extravasation across microvascular endothelium in response to vpf/vegf and other vasoactive mediators. Microcirculation 1999;6:23-44.

25 McDonald DM, Thurston G, Baluk P. Endothelial gaps as sites for plasma leakage in inflammation. Microcirculation 1999;6:7-22.

26 Feng D, Nagy J, Dvorak H, et al. Ultrastructural studies define soluble macromolecular, particulate, and cellu- 
lar transendothelial cell pathways in venules, lymphatic vessels, and tumor-associated microvessels in man and animals. Microsc Res Tech 2002;57:289-326.

27 Hashizume H, Baluk P, Morikawa S, et al. Openings between defective endothelial cells explain tumor vessel leakiness. Am J Pathol 2000;156:1363-1380.

28 Roberts WG, Palade GE. Neovasculature induced by vascular endothelial growth factor is fenestrated. Cancer Res 1997;57:765-772.

29 Kuo CJ, Farnebo F, Yu EY, Christofferson R, Swearingen RA, Carter R, et al. Comparative evaluation of the antitumor activity of antiangiogenic proteins delivered by gene transfer. Proc Natl Acad Sci USA 2001;98: 4605-4610.

30 Shih SC, Smith LE. Quantitative multi-gene transcriptional profiling using real-time pcr with a master template. Exp Mol Pathol 2005;79:14-22.

31 Aerts JL, Gonzales MI, Topalian SL. Selection of appropriate control genes to assess expression of tumor antigens using real-time rt-pcr. Biotechniques 2004;36:84-86, 88, 90-91.

32 Graham MM, Evans ML. A simple, dual tracer method for the measurement of transvascular flux of albumin into the lung. Microvasc Res 1991;42:266-279.

33 Dvorak AM. Procedural guide to specimen handling for the ultrastructural pathology service laboratory. JElec Microsc Tech 1987;6:255-301.

34 Nagy JA, Dvorak AM, Dvorak HF. VEGF-A ${ }^{164 / 5}$ and PlGF. Roles in angiogenesis and arteriogenesis. Trends Cardiovasc Med 2003;13:169-175.

35 Nagy JA, Vasile E, Feng D, et al. Vascular permeability factor/vascular endothelial growth factor induces lymphangiogenesis as well as angiogenesis. J Exp Med 2002;196:1497-1506.

36 Dvorak AM, Kohn S, Morgan ES, et al. The vesiculovacuolar organelle (VVO): a distinct endothelial cell structure that provides a transcellular pathway for macromolecular extravasation. J Leukoc Biol 1996;59: 100-115.

37 Brown LF, Yeo KT, Berse B, et al. Expression of vascular permeability factor (vascular endothelial growth factor) by epidermal keratinocytes during wound healing. J Exp Med 1992;176:1375-1379.

38 Ren G, Michael LH, Entman ML, et al. Morphological characteristics of the microvasculature in healing myocardial infarcts. J Histochem Cytochem 2002;50: $71-79$.
39 Detmar M, Brown LF, Claffey KP, et al. Overexpression of vascular permeability factor/vascular endothelial growth factor and its receptors in psoriasis. J Exp Med 1994;180:1141-1146.

40 Dvorak HF, Orenstein NS, Carvalho AC, et al. Induction of a fibrin-gel investment: an early event in line 10 hepatocarcinoma growth mediated by tumor-secreted products. J Immunol 1979;122:166-174.

41 Neal CR, Michel CC. Transcellular gaps in microvascular walls of frog and rat when permeability is increased by perfusion with the ionophore A23187. J Physiol 1995;488(Part 2):427-437.

42 Feng D, Nagy JA, Hipp J, et al. Reinterpretation of endothelial cell gaps induced by vasoactive mediators in guinea-pig, mouse and rat: many are transcellular pores. J Physiol 1997;504(Part 3):747-761.

43 Dvorak HF, Harvey VS, McDonagh J. Quantitation of fibrinogen influx and fibrin deposition and turnover in line 1 and line 10 guinea pig carcinomas. Cancer Res 1984;44:3348-3354.

44 Duval M, Bedard-Goulet S, Delisle C, et al. Vascular endothelial growth factor-dependent down-regulation of FLK-1/KDR involves Cbl-mediated ubiquitination. Consequences on nitric oxide production from endothelial cells. J Biol Chem 2003;278:20091-20097.

45 Lopez JJ, Laham RJ, Carrozza JP, et al. Hemodynamic effects of intracoronary VEGF delivery: evidence of tachyphylaxis and no dependence of response. Am J Physiol 1997;273:H1317-H1323.

46 Stan RV, Kubitza M, Palade GE. PV-1 is a component of the fenestral and stomatal diaphragms in fenestrated endothelia. Proc Natl Acad Sci USA 1999;96:1320313207.

47 Stan RV, Ghitescu L, Jacobson BS, et al. Isolation, cloning, and localization of rat PV-1, a novel endothelial caveolar protein. J Cell Biol 1999;145:1189-1198.

48 Feng D, Nagy JA, Brekken RA, et al. Ultrastructural localization of the vascular permeability factor/vascular endothelial growth factor (VPF/VEGF) receptor-2 (FLK-1, KDR) in normal mouse kidney and in the hyperpermeable vessels induced by VPF/VEGF-expressing tumors and adenoviral vectors. J Histochem Cytochem 2000;48:545-556.

49 Feng D, Nagy JA, Pyne K, et al. Ultrastructural localization of platelet endothelial cell adhesion molecule (PECAM-1, CD31) in vascular endothelium. J Histochem Cytochem 2004;52:87-101. 